\title{
Influence of moisture content on the contact angle and surface tension measured on birch wood surfaces
}

\author{
Rami Benkreif ${ }^{1} \cdot$ Fatima Zohra Brahmia $^{1} \cdot$ Csilla Csiha $^{1}[$
}

Received: 10 February 2020 / Accepted: 4 February 2021 / Published online: 12 March 2021

(c) The Author(s) 2021

\begin{abstract}
Surface tension of solid wood surfaces affects the wettability and thus the adhesion of various adhesives and wood coatings. By measuring the contact angle of the wood, the surface tension can be calculated based on the Young-Dupré equation. Several publications have reported on contact angle measured with different test liquids, under different conditions. Results can only be compared if the test conditions are similar. While the roles of the drop volume, image shooting time etc., are widely recognized, the role of the wood surface moisture content (MC) is not evaluated in detail. In this study, the effect of wood moisture content on contact angle values, measured with distilled water and diiodomethane, on sanded birch (Betula pendula) surfaces was investigated, in order to find the relationship between them. With increasing MC from approximately $6 \%$ to $30 \%$, increasing contact angle (decreasing surface tension) values were measured according to a logarithmic function. The function makes possible the calculation of contact angles that correspond to different MCs.
\end{abstract}

\section{Introduction}

The surface of machined wood products may need to be treated with wood preservatives, stains, coatings, adhesives or other materials to improve their properties. The surface tension of solid wood surfaces (also known as surface-free energy) affects its wettability and thus the adhesion of various coatings and adhesives. Increasing the surface tension of wood and/or at the same time decreasing the surface tension of the applied liquid are the ways to improve wetting and adhesion. Surface tension is not directly measurable, it is usually calculated from the Young Dupré equation, using the measured value of the contact angle (Zenkiewicz 2007). Young (1805) stated that for a homogenous and ideally smooth surface, the contact angle of a wetting drop is described by the following equation:

$\cos \theta=\frac{\gamma s v-\gamma s l}{\gamma l v}$

Csilla Csiha

csiha.csilla@uni-sopron.hu

1 Simonyi Károly Faculty of Engineering, Wood Sciences and Applied Art, Institute of Wood Based Products and Technologies, University of Sopron, Bajcsy-Zs. u. 4, Sopron 9400, Hungary where $\gamma_{\mathrm{sv}}$ is the surface tension at the solid-vapour interface, $\gamma_{\mathrm{sl}}$ is the surface tension at the solid-liquid interface and $\gamma_{\mathrm{lv}}$ is the surface tension at the liquid-vapour interface. The contact angle $\theta$ is formed between a drop of liquid ( $a$ demi sphere) placed on a solid surface and the tangential drawn to the drop in the point of intersection. Contact angles greater than $90^{\circ}$ (high contact angle) generally mean that wetting of the surface is unfavourable, whilst contact angles smaller than $90^{\circ}$ correspond to high wettability and it can be expected that the liquid will spread well. The Young's equation has more than one unknown, so different models were developed to offer a solution to calculate the surface tension of the solid: Fowkes theory, harmonic mean equation, Wendt Owens model, the acid-base model, the equation of state model, - also referred to as single liquid or Neumann's model (Neumann et al. 1974), etc. The equation of state involves one single test liquid, the other theories involve at least two test liquids, a polar one and a dispersive one, the acid-base model involves at least three. Gindl et al. (2001) reported that the different methods result in different surface energy values. They found that tree methods offer relatively similar surface free energy values: the equation of state, the geometric mean and the acid base method. The literature shows that the harmonic mean and the geometric mean equations are often used to calculate the surface tension of a solid surface, for several different purposes. This was the reason why the Fawkes method was chosen to calculate the 
surface tension of the solid. In all these theories, distilled water (DW) is one of the most suitable liquids to be used as polar component, and diiodomethane (DIM) (among other test liquids) is a commonly used dispersive test liquid (Oberhofnerova and Panek 2016; Qin et al. 2014; Mohammed Ziegler et al. 2006; Jankowska et al. 2018; Laskowska and Kozakeiwicz 2017). To allow possible comparison of the results, distilled water was chosen as the polar component and diiodomethane as dispersive component. As the different methods offer slightly different surface tension results, it is worth emphasizing that the surface energy of a solid is not an exact value. Rather, it is a value that depends on which liquid is selected for contact angle testing, and which surface energy theory is selected for data analysis. The calculated surface tension of a solid is primarily suitable for the evaluation of differences occurring during an ongoing process, rather than being the absolute value of the surface tension (Krüss GmbH 1999).

Since distilled water is a polar liquid, and the wood itself is a hygrophilic material, it is expected that wood MC will also affect the shape of the contact angle. When searching in the literature, most of the time the MC of the samples is reported, but in the absence of a standard developed specially for contact angle measurement of wood surfaces (Molnár et al. 2018), the values cover a wide range. Wood is sensitive to water, constantly changing its own MC according to the water vapour content of the environment. Several results have been reported on different properties of wood, which are significantly influenced by the moisture content of the wood. Tudor et al. (2020) reported that the MC of larch wood bark, bonded with 5 different adhesives, had a more significant effect on the adhesion and formaldehydeemission of the decorative panels, than the size of the particle fraction. Qin et al. (2014) measured with distilled water, diiodomethane and formamide the wettability of differently machined poplar wood with the harmonic mean (WORK) method. The surface roughness of the samples was also taken into account by calculating the average roughness $R_{a}$, whilst no data on the MC of the samples was reported. Jankowska et al. (2018) evaluated the effect of sawing, sanding and flat slicing on European oak samples with an MC between 7 and $8 \%$ and calculated the surface free energy with the Wendt Owens model, based on contact angle measurements using distilled water, diiodomethane and formamide.Mantanis and Young (1997) reported measurement of surface free energy on samples of two softwood species: sitka sprouce and Douglas fir and two hardwood species: sugar maple and aspen. The samples had a moisture content between 6 and $7 \%$. Nzokou and Kasmdem (2004) investigated the effect of wood extractives on the wettability of two hardwoods (black cherry and red oak) and one softwood (red pine), on samples with $12 \%$ moisture content. Nussbaum (1999) examined surface wettability to evaluate wood surface inactivation, on Scots pine and Norway spruce samples of $16 \%$ MC. Korowska and Kozakiewicz (2016) investigated the wettability of gaboon wood samples of $9.6 \%$ average MC. Bekhta et al. (2018) investigated the dynamic contact angle of the tight and loose sides of thermally compressed and densified, tangentially cut birch veneer at 5\% MC. Oberhofnerová and Panek (2016) exposed samples of 9 different wood species to natural weathering over a 12 month period. Wettability was monitored by sessile drop method, using distilled water. Because the samples exhibited different MC due to varying outdoor conditions, they conditioned the samples to a $12 \pm 2 \% \mathrm{MC}$, prior to each contact angle measurement, as recommended by Kudela et al.(2015). Kudela et al. (2015) investigated the effect of moisture content on wettability and surface free energy of beech wood. It was found that the contact angles increased with increasing moisture content of the wood over the bound water range. Surface free energy was calculated by the Neumann method, while the disperse and the polar components of the surface tension were calculated using equations proposed by Kloubek (1974) after detecting the contact angle with distilled water, diiodomethane, ethylene glycol, formamide and $\alpha$-bromonaphtalene. Surface free energies were reported to decrease with increasing MC over the entire moisture range. De Meijer et al. (2000) reported contact angle measurements with diiodomethane, formamide and water, on spruce and meranti samples with $7 \%, 12 \%$ and $25 \%$ MC. Increasing MC resulted in decreasing contact angle when it was measured with water, but with diiodomethane the contact angle increased. This was not the case of meranti, where increasing $\mathrm{MC}$ was associated with increasing contact angle, both with water and diiodomethane. Scheikl and Dunky (1998) also studied the influence of moisture content by wetting with water. They found that, apart from few exceptions, there was no decisive influence of the wood moisture content on the surface tension of various solid wood surfaces, in spite of rather lower contact angle at surfaces of higher wood moisture content. Finally, no consistent trend was reported. To have comparable results, the generalized relation between the $\mathrm{MC}$ and the contact angle would be needed.

\section{Materials and methods}

In this study, the focus was on finding the relationship between the moisture content of the wood, (ranging from 6 to $30 \%$ ), and the apparent contact angle (Wenzel 1936), measured both with a polar (distilled water) and a dispersive liquid (diiodomethane). The surface tension values were calculated from the contact angle values of DW and DIM, according to Fowkes. To obtain the real trend of variation, it was attempted to exclude the distorting effect of a possibly increasing roughness during the moistening 
of the samples. In this sense, all samples were soaked in distilled water prior to the measurements. The samples were placed in a drying chamber and taken out for measurements during the drying process. This way the distorting effect of roughness was minimised.

For this study, 50 samples were prepared, with tangential surfaces and dimensions of $50 \mathrm{~mm} \times 80 \mathrm{~mm} \times 20 \mathrm{~mm}$, from birch (Betula pendula) wood, with an average density of $\rho=578.24 \mathrm{~kg} / \mathrm{m}^{3}(\mathrm{STD}=0.31$, var $=0.09)$. The surface of the samples was sanded with sand paper of grit size 120 . For this study, a wood species was selected that has a relatively homogeneous anatomical structure, free from large open pores (which could have had a distortive effect on the contact angle) and sanded, because sanding is reported to result in a smooth surface (Magoss 2015; Gurau et al. 2009). To minimize the distorting effect of a continuously changing surface roughness during the measurements, samples were soaked in distilled water above a moisture content of $30 \%$. Following soaking, all the samples were placed into a climate chamber (programmable), at $60{ }^{\circ} \mathrm{C} \pm 3$. The MC of the samples started to decrease. A temperature-MC diagram was used, to set the drying time and to estimate the expected MC of the samples, but the actual MC of the samples was measured by the Kern MLB 50-3N Moisture analyzer instrument. This device is designed for fast and reliable determination of $\mathrm{MC}$ in porous or solid materials, by applying thermogravimetric method. Thin slices from the sample's sides were cut, using sharp slicer.

The slices were placed on the sample holder plate of the Kern MLB 50-3N Moisture analyzer instrument, which displayed digitally the actual MC value after 2-3 min, depending on the MC of the sample. Higher MC needed longer time. The contact angle was measured simultaneously on both sides of the sample: with distilled water on one side and diiodomethane on the other side. After measuring the contact angle with DW and DIM, the surface tension of the surfaces was calculated by Fowkes method, using the following equations:

$\gamma_{S}^{D}=\left(\gamma_{L} / 4\right)(\cos \theta+1)^{2}$

$\left(\gamma_{S}^{D} \gamma_{L}^{D}\right)^{1 / 2}+\left(\gamma_{S}^{P} \gamma_{L}^{P}\right)^{1 / 2}=\gamma_{L}(\cos \theta+1) / 2$

where: $\gamma_{S}^{D}$ is the dispersive component of the solid, $\gamma_{S}^{P}$ is the polar component of the solid, $\gamma_{L}^{D}$ is the dispersive component of the liquid, $\gamma_{L}^{P}$ is the polar component of the liquid, $\gamma_{L}=\gamma_{L}^{D}$ is the dispersive component of the liquid as DIM has only dispersive component.

The contact angle was measured using PG-X Goniometer and the sessile drop method. During the measurements, two similar PG-X goniometers were used, to reduce any differences in test conditions between the distilled water and diiodomethane measurements. During the drying process, the samples were tested at the following moisture contents: $29.97,17.96,16.20,14.11,12.16,10.10,7.99$, $6.03 \%$. A total of 25 measurements were taken with each test liquid, for each moisture content. The size of the testing droplet has to be adjusted prior to the measurements. The effect of droplet size on contact angle has always been an issue and appears to have a significant effect on rough surfaces (Amrei et al. 2017; Eid et al. 2018). In the actual study, a drop of $5 \mu \mathrm{l}$ volume was used. The tests were performed in dynamic mode. The apparent contact angle was recorded at $1 \mathrm{~s}$. The surface roughness of the samples was also measured during drying, with a MAHR S2 Perthometer instrument, having a stylus tip of $2 \mu \mathrm{m}$ diameter. Ten roughness measurements were taken on 5 samples, in each moisture content range. On each tested sample, linear roughness measurements were taken perpendicular to the grain, with a $50 \mu \mathrm{m}$ distance between the 10 consecutive measurements taken on the same sample, thus a "surface like" palpation of sample portion was achieved. The unfiltered P,- primary profile was evaluated by $\mathrm{R}_{\mathrm{a}}$ the average roughness (Magoss 2008), as per DIN EN ISO 4288 (1998) standard. The average maximum peak to valley $R_{z}$ and the maximum roughness $R_{\max }$ were also measured.

\section{Results and discussion}

When measuring the roughness of samples soaked in distilled water and then artificially dried from a MC higher than $30 \%$, the average $R_{a}$ roughness of the samples (Table 1), attributed to different moisture content levels, showed a linear and mostly horizontal relationship, according to the equation:

$y=a x+b$,

where $a=5.55$ and $b=9.69$ (Fig. 1). The difference between the roughness belonging to the highest $\mathrm{MC}$ and the lowest one was $0.98 \mu \mathrm{m}$, being $8.61 \%$ difference.

Pairwise comparison of mean $\mathrm{R}_{\mathrm{a}}$ values shows that there is a significant difference between the $29.97 \%$ MC and $6.03 \%$ to $17.96 \% \mathrm{MC}$ results. Linear regression analysis (LRA) showed that between $6.03 \% \mathrm{MC}$ and $17.96 \%$ $\mathrm{MC}$ there are no significant differences in the surface roughness values, but the roughness values of $29.97 \% \mathrm{MC}$ differ significantly from the previous ones. The roughness results for $29.97 \% \mathrm{MC}$ are significantly different from the other MC groups with one way ANOVA (Table 2) and the Fisher LSD test (Table 3) too (dependent variable: Ra). 
Table $1 \mathrm{R}_{\mathrm{a}}$ average roughness $(\mu \mathrm{m}), \mathrm{R}_{\mathrm{z}}$ the average maximum peak to valley $(\mu \mathrm{m})$ and $R_{\max }$ maximum roughness $(\mu \mathrm{m})$ of birch samples recorded during drying at different levels of MC (\%)

\begin{tabular}{lrrrrrrrr}
\hline & $6.03 \%$ & $7.99 \%$ & $10.1 \%$ & $12.16 \%$ & $14.11 \%$ & $16.2 \%$ & $17.96 \%$ & $29.97 \%$ \\
\hline Ra $(\mu \mathrm{m})$ & & & & & & & & \\
Mean & 10.40 & 10.12 & 10.25 & 10.31 & 10.47 & 10.52 & 10.72 & 11.38 \\
SD & 1.34 & 0.75 & 0.79 & 0.94 & 1.12 & 0.86 & 0.57 & 0.55 \\
Rz $(\mu \mathrm{m})$ & & & & & & & & \\
Mean & 58.182 & 60.03 & 61.91 & 63.03 & 65.96 & 67.72 & 69.63 & 77.68 \\
SD & 9.80 & 9.83 & 8.48 & 7.03 & 8.13 & 5.34 & 8.47 & 6.72 \\
Rmax $(\mu \mathrm{m})$ & & & & & & & & \\
Mean & 81.88 & 83.67 & 85.22 & 87.91 & 90.55 & 93.54 & 95.02 & 108.08 \\
SD & 25.55 & 14.87 & 14.05 & 16.99 & 13.24 & 13.66 & 6.61 & 11.49 \\
\hline
\end{tabular}

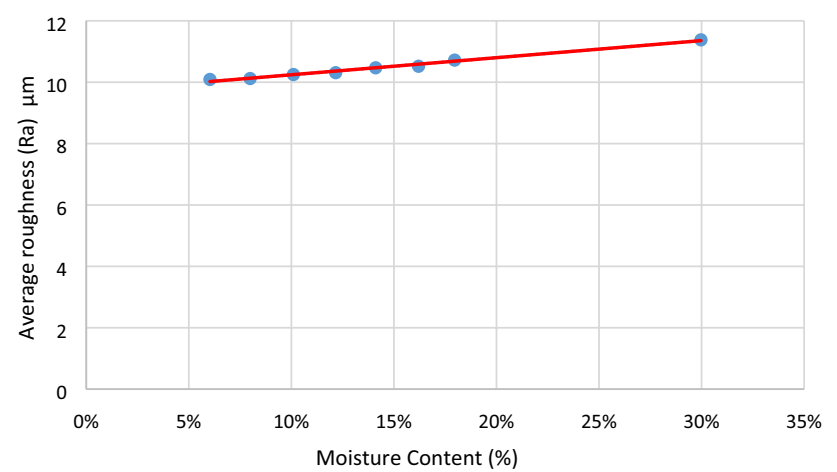

Fig. $1 \mathrm{R}_{\mathrm{a}}$ average roughness $(\mu \mathrm{m})$ of birch samples recorded during drying, at different levels of MC

Table 2 One way ANOVA univariate test of significance for comparison of Ra vs MC

\begin{tabular}{llllll}
\hline Source & $\begin{array}{l}\text { Sum of } \\
\text { Squares }\end{array}$ & $\begin{array}{l}\text { Degr. of } \\
\text { Freedom }\end{array}$ & $\begin{array}{l}\text { Mean } \\
\text { Square }\end{array}$ & F & p \\
\hline
\end{tabular}

ANOVA test for samples with MC from $6.03 \%$ to $17.96 \%$ )

$\begin{array}{lrllll}\text { Effect } & 0.21425 & 1 & 0.214245 & 0.263086 & 0.609578 \\ \text { Error } & 58.63336 & 72 & 0.814352 & \end{array}$

ANOVA test for samples with MC from $6.03 \%$ to $29.97 \%$ )

\begin{tabular}{lllrrr} 
Effect & 11.37502 & 1 & 11.37502 & 13.96818 & 0.00037 \\
Error & 58.63336 & 72 & 0.81435 & & \\
\hline
\end{tabular}

The contact angle of sanded birch samples as a function of moisture content (MC), measured with distilled water (Fig. 2.a) showed a logarithmic relationship according to the following equation:

$\mathrm{y}=\mathrm{a}_{\mathrm{DW}} \ln (\mathrm{x})+\mathrm{b}_{\mathrm{DW}}$

where $a_{D W}=11.251$ and $b_{D W}=96.772$. The determination coefficient $\mathrm{R}^{2}=0.97$ suggests a strong correlation between the variables and the function.

When measured with distilled water, a $2 \%$ variation in MC from $6.03 \%$ to $7.99 \%$ resulted in a $5.58^{\circ}$ deviation in the value of the contact angle, which corresponds to an increase of $8.17 \%$. Taking the $6.03 \% \mathrm{MC}$ as a reference value, an increase to $10.10 \% \mathrm{MC},-12.16 \% \mathrm{MC}$,14.11\% MC,- $16.20 \% \mathrm{MC},-17.96 \% \mathrm{MC}$,- and $29.97 \% \mathrm{MC}$, increased the contact angle value by $11.71 ; 15.75 ; 15.76$; $20.03 ; 21.08$; and $29.29 \%$, respectively. According to the measurements, the smallest difference between two contact angle data measured with distilled water was $0.25^{\circ}$, which was the difference between MC $12.16 \%$ and MC $10.10 \%$. While increasing the MC by $2 \%$, the highest difference in the contact angle values was recorded between $6.03 \% \mathrm{MC}$ and $7.99 \% \mathrm{MC}$, being: $5.58^{\circ}$, causing a $7.99 \%$ increase in the contact angle (Table 4). All these differences are significant based on the pairwise analysis of the " $t$ " test $(\mathrm{p}=0.05)$.

The contact angle of sanded birch samples as a function of moisture content (MC), measured with diiodomethane
Table 3 Fisher LSD test: Ra vs MC varying from $6.03 \%$ to 29.97

\begin{tabular}{llllllllll}
\hline & MC\% & $\{1\}$ & $\{2\}$ & $\{3\}$ & $\{4\}$ & $\{5\}$ & $\{6\}$ & $\{7\}$ & $\{8\}$ \\
& & 10.092 & 10.118 & 10.254 & 10.306 & 10.472 & 10.515 & 10.722 & 11.385 \\
\hline 1 & 6.03 & & 0.949597 & 0.690211 & 0.598244 & 0.350055 & 0.298534 & 0.123129 & 0.002027 \\
2 & 7.99 & 0.949597 & & 0.73729 & 0.642736 & 0.383314 & 0.32855 & 0.138859 & 0.002454 \\
3 & 10.1 & 0.690211 & 0.73729 & & 0.897641 & 0.590573 & 0.519707 & 0.249925 & 0.006506 \\
4 & 12.16 & 0.598244 & 0.642736 & 0.897641 & & 0.682055 & 0.606133 & 0.306087 & 0.009278 \\
5 & 14.11 & 0.350055 & 0.383314 & 0.590573 & 0.682055 & & 0.915443 & 0.537563 & 0.026698 \\
6 & 16.2 & 0.298534 & 0.32855 & 0.519707 & 0.606133 & 0.915443 & & 0.609578 & 0.034446 \\
7 & 17.96 & 0.123129 & 0.138859 & 0.249925 & 0.306087 & 0.537563 & 0.609578 & & 0.104779 \\
8 & 29.97 & 0.002027 & 0.002454 & 0.006506 & 0.009278 & 0.026698 & 0.034446 & 0.104779 & \\
\hline
\end{tabular}


Fig. 2 a Contact angle as a function of MC measured with DW. b Contact angle as a function of MC measured with DIM. c Surface tension of birch wood surfaces as a function of MC

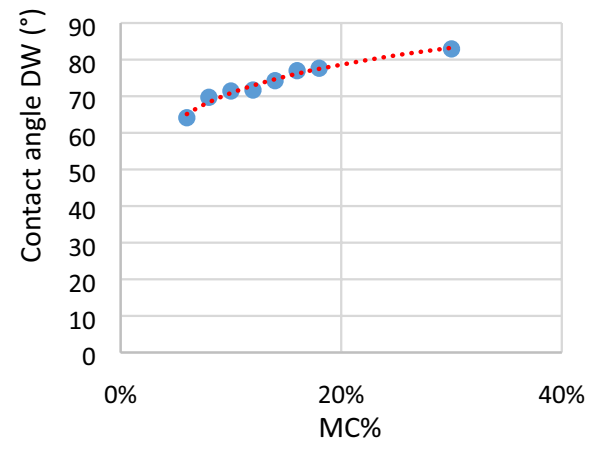

(a)

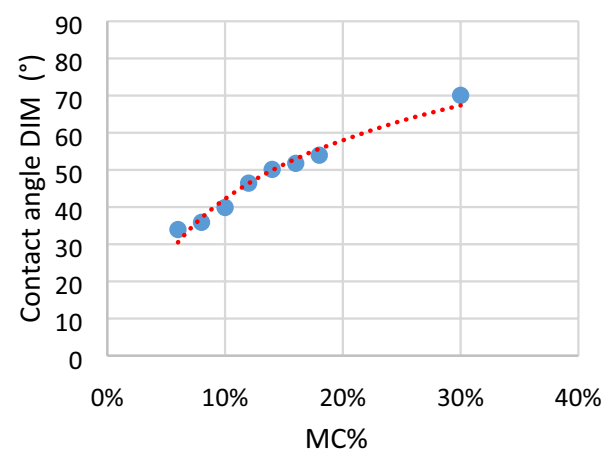

(b)

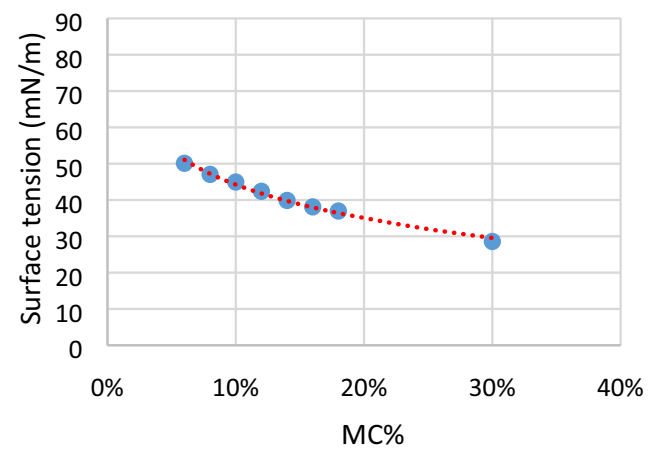

(c)

Table 4 Contact angle $\left({ }^{\circ}\right)$ and surface tension $(\mathrm{mN} / \mathrm{m})$ of birch samples at different MC

\begin{tabular}{lrrrrrrrr}
\hline MC birch & $6.03 \%$ & $7.99 \%$ & $10.1 \%$ & $12.16 \%$ & $14.11 \%$ & $16.2 \%$ & $17.96 \%$ & $29.97 \%$ \\
\hline DW $\left(^{\circ}\right)$ & & & & & & & & \\
Mean & 64.13 & 69.71 & 71.43 & 71.69 & 74.24 & 76.98 & 77.65 & 82.92 \\
SD & 4.74 & 6.74 & 4.83 & 6.40 & 8.00 & 10.41 & 8.40 & 16.32 \\
DIM $\left(^{\circ}\right)$ & & & & & & & & \\
Mean & 33.95 & 35.89 & 39.88 & 46.44 & 50.14 & 51.77 & 53.96 & 70.07 \\
SD & 4.79 & 5.63 & 7.88 & 10.20 & 9.53 & 11.90 & 7.30 & 9.45 \\
ST (mN/m) & & & & & & & & \\
Mean & 50.11 & 47.05 & 44.94 & 42.39 & 39.88 & 38.1 & 36.96 & 28.58 \\
SD & 2.73 & 3.69 & 2.82 & 8.98 & 5.03 & 7.06 & 3.42 & 8.86 \\
\hline
\end{tabular}

DW: distilled water; DIM: diiodomethane; ST: surface tension
(Fig. 2b) showed a logarithmic relation according to the following equation:

$\mathrm{y}=\mathrm{a}_{\text {DIW }} \ln (\mathrm{x})+\mathrm{b}_{\text {DIW }}$

where $\mathrm{a}_{\mathrm{DIM}}=22.90$ and $\mathrm{b}_{\text {DIM }}=94,94$. The determination coefficient $\mathrm{R}^{2}=0.968$ suggests the same strong correlation between the variables and the function.

Both the polar and the dispersive liquid is sensitive to the moisture content of the wood. Higher moisture content of the wood surface resulted in higher values of the contact angle.

When the contact angle was measured with diiodomethane, the increase in MC from $6.03 \%$ to $7.99 \%$ resulted in a $1.94^{\circ}$ deviation in the value of the contact angle. Considering the $6.03 \% \mathrm{MC}$ as a reference value, the increase to $10.10 \% \mathrm{MC}$,- $12.16 \% \mathrm{MC},-14.11 \% \mathrm{MC},-16.20 \% \mathrm{MC}$,$17.96 \% \mathrm{MC}$,- and $29.97 \% \mathrm{MC}$, increased the value of the contact angle by $17.46 ; 36.78 ; 47.68 ; 52.48 ; 58.93$; and $106.39 \%$, respectively (Table 4). All these differences are significant based on t test's pairwise analysis $(p=0.05)$.

One way ANOVA showed that between $6.03 \%$ and $29.97 \% \mathrm{MC}$, there is a significant influence of the MC on the values of the contact angle, while the differences between the surface roughness values are not significant in the 6-18\% MC range. Analysis of variances proved 
the correctness of all assumptions, as the variance was homogeneous.

The surface tension of sanded birch samples as a function of moisture content (MC), measured with distilled water and diiodomethane, showed a logarithmic relationship according to the equation (Fig. 2.c)

$\mathrm{y}=\mathrm{a}_{\mathrm{birch}} \ln (\mathrm{x})+\mathrm{b}_{\text {birch }}$

where $a_{\text {birch }}=-13.36$ and $b_{\text {birch }}=13.47$. The determination coefficient was $\mathrm{R}^{2}=0.99$, suggesting a strong correlation between the variables and the function and showed that the contact angle of the wood surface is sensitive to the MC of the wood.

An increase in $\mathrm{MC}$ from $6.03 \%$ to $7.99 \%$ resulted in a $3.06 \mathrm{mN} / \mathrm{m}$ deviation in the value of the surface tension. Considering the $6.03 \% \mathrm{MC}$ as a reference value, an increase to $7.99 \% \mathrm{MC}$,- $10.10 \% \mathrm{MC},-12.16 \% \mathrm{MC}$,- $14.11 \% \mathrm{MC}$,$16.20 \% \mathrm{MC}$,- $17.96 \% \mathrm{MC}$,- and $29.97 \% \mathrm{MC}$, decreased the value of the surface tension with $6.1,-10.31,-15.4,-20.41$,23.96,- 26.24,- and 42.96\%, respectively (Table 2). All these differences are significant based on t test's pairwise analysis $(\mathrm{p}=0.05)$.

These results cope with the results obtained with DIM by de Meijer et al. (2000) on spruce and meranti surfaces, which were tested at approximately 7, 12 and $25 \% \mathrm{MC}$, as it was reported, that increasing wood MC increases the DIM contact angle. For these wood species the results were controversial when measured with water. The roughening effect of increasing MC was not discussed as possible cause. The upper results obtained for birch surfaces also are in line with the findings reported by Kudela et al. (2015). Radially cut beech wood surfaces were studied at MC of 3.9, 9.7, 12.9, $19.4,24$, and $26.1 \%$ and it was reported with regard to DW and DIM that the surface free energy decreased with increasing MC. It was also stated that the surface free energy of beech wood, determined with distilled water, was higher than with other test liquids. This statement also is in line with the current findings, although the beech wood's surface tension calculation was done according to Kloubek (1974). The contact angle data published on beech wood cannot be precisely compared with the current values of birch wood, as for the evaluation of beech the contact angle $\theta_{0}$ from the beginning of the wetting process was used (beside $\theta_{u}$, picked up at the moment when the drop's receeding starts), contrary to the one used in this study, recorded at $1 \mathrm{~s}$ after release. A further difference is that a droplet of $1.8 \mu$ l volume was used, contrary to the $5 \mu \mathrm{l}$ drop volume of the present study. No data on the beech wood surface roughness are reported, neither similar MC values, except the $12.9 \%$ MC. Despite the different conditions, a comparison of the results of both the studies was made around $12 \% \mathrm{MC}$. Contact angle measured with DW, on beech, is reported for an MC of $12.9 \%$ by Kudela et al. (2015) to be $70^{\circ}$, and in the actual study on birch surfaces it is $71.69^{\circ}$, at an MC of $12.16 \%$. The contact angle measured by Kudela et al. (2015) with DIM for an MC of $12.9 \%$ on beech wood is reported to be $38.5^{\circ}$, in the actual study it is $46.44^{\circ}$, at an MC of $12.16 \%$ on birch surfaces. There is no function reported for the relation of $\mathrm{MC}$ with the contact angle/surface free energy of beech surfaces. At the same time the logarithmic equations (Eq. 5 and Eq. 6) set for the contact angle of birch surfaces, fit the contact angle data of beech surfaces, with the complement that the "a" and "b" values differ from the birch wood's constants. To set the equation for beech and other wood species, the same parameters must be measured under similar conditions. It is planned to widen the present studies by establishing this type of relationship for other wood species too.

\section{Conclusion}

Based upon contact angle measurements taken on similarly sanded birch (Betula pendula) surfaces, which had different $\mathrm{MC}$, revealed that the variation of moisture content has a significant effect both on the contact angle and on the surface tension values. The contact angle of sanded birch samples as a function of moisture content (MC), measured with distilled water and diiodomethane increases according to the following logarithmic relation: $y=a \ln (x)+b$, (the " $a$ " and "b" coefficients are specific to DW and DIM). The function makes it possible to calculate the contact angles corresponding to different MCs. The surface tension of sanded birch samples as a function of moisture content (MC), measured with distilled water and diiodomethane, shows a decrease according to a logarithmic relation of the form $y=a \ln (x)+b$ (where $a=-13.46 ; b=13.47$ ). Analysis of variances proved the correctness of all assumptions, as the variance was homogeneous. The distorting effect of increasing MC was greater than $5 \%$ both for contact angles with distilled water and diiodomethane, and for surface tension too.

Acknowledgements This article was made in frame of the „EFOP3.6.1-16-2016-00018-Improving the role of research+ development+ innovation in the higher education through institutional developments assisting intelligent specialization in Sopron and Szombathely".

Funding Open access funding provided by University of Sopron.

\section{Compliance with ethical standards}

Conflict of interest Authors state that there is no conflict of interest.

Open Access This article is licensed under a Creative Commons Attribution 4.0 International License, which permits use, sharing, adaptation, distribution and reproduction in any medium or format, as long as you give appropriate credit to the original author(s) and the source, provide a link to the Creative Commons licence, and indicate if changes 
were made. The images or other third party material in this article are included in the article's Creative Commons licence, unless indicated otherwise in a credit line to the material. If material is not included in the article's Creative Commons licence and your intended use is not permitted by statutory regulation or exceeds the permitted use, you will need to obtain permission directly from the copyright holder. To view a copy of this licence, visit http://creativecommons.org/licenses/by/4.0/.

\section{References}

Amrei MM, Davoudi M, Chase GG, Tafreshi HV (2017) Effects of roughness on droplet apparent contact angles on a fibre. Sep Purif Technol 180:107-113

Bekhta P, Krystofiak T, Proszyk S, Lis B (2018) Evaluation of dynamic contact angle of loose and tight sides of thermally compressed birch wood. Drvna Ind 69(4):387-394

de Meijer M, Haemers S, Cobben W, Militz H (2000) Surface energy determinations of wood: comparison of methods and wood species. Langmuir 16(24):9352-9359

DIN EN ISO 4288 (1998) Geometrical Product Specifications (GPS) surface texture: profile method-rules and procedures for the assessment of surface texture (ISO 4288:1996); German version EN ISO 4288:1997

Eid KF, Path M, Sommers AD (2018) The physics of water droplets on surfaces exploring the effects of roughness and surface chemistry. Eur J Phys 39:1-21

Fowkes FM (1968) Calculation of work of adhesion by pair potential summation. J Colloid Interface Sci 28(1968):493-505

Gindl M, Sinn G, Reiterer A, Tschegg S (2001) Wood surface energy and time dependence of wettability: a comparison of different wood surfaces using an acid-base approach. Holzforschung 55:433-440

Gurau L, Mansfield-Williams H, Irle M (2009) Form error removal of sanded wood surfaces. Eur J Wood Prod 67:219-227

Jankowska A, Zbieć M, Kozakiewicz P, Koczan G, Oleńska S, Beer P (2018) The wettability and surface free energy of sawn, sliced and sanded european oak wood. Maderas Ciencia Tecnol 20(3):443454. https://doi.org/10.4067/S0718-221X2018005031401

Kloubek J (1974) Calculation of surface free energy components of ice according to its wettability by water, chlorbenzene and carbon disulfide. J Colloid Interface Sci 46:185-190

Korowska A, Kozakiewicz P (2016) Determination of the wettability of gaboon wood (Aucoumea klaineana Pierre). Forestry Wood Technol No 93:89-93

Krüss GmbH (1999) Technical Note TN306e Models for Surface Free Energy calculation. kruss-scientific.com. https://www.kruss-scien tific.com/fileadmin/user_upload/website/literature/kruss-tn306en.pdf. Accessed 03.02.2020

Kudela J, Wesserle F, Baksa J (2015) Influence of moisture content of beech wood on wetting and surface free energy. Acta Facultatis Xylologiae Zvolen 57(1):25-35
Laskowska A, Kozakeiwicz P (2017) Surface wettability of wood species from tropical and temerate zones by polar and despersive liquids. Drvna Ind 68(4):299-306. https://doi.org/10.5552/deind. 2017.1704

Magoss E (2008) General regularities of wood surface roughness. Acta Silv Lign Hung 4:81-93

Magoss E (2015) Evaluating of the Surface roughness of sanded wood. Wood Res 60(5):783-790

Mantanis GI, Young RA (1997) Wetting of wood. Wood Sci Technol 31:339-353

Mohammed-Ziegler I, Horvolgyi Z, Toth A, Forsling W, Holmgren A (2006) Wettability and spectroscopic characterization of silylated wood samples. Polym Adv Technol 17:932-939

Molnár Z, Magoss E, Fuchs I, Csiha C (2018) Stability of thermosmoothed and precision planed solid wood surfaces. Eur J Wood Prod 76(1):243-249

Neumann AW, Good RJ, Hope CJ, Sejpol M (1974) An equation-ofstate approach to determine surface tension of low-energy solids from contact angles. J Colloid Interface Sci 49(1974):291-304

Nussbaum RM (1999) Natural surface inactivation of Scots pine and Norway spruce evaluated by contact angle measurements. Holz Roh- Werkst 57:419-424

Nzokou P, Kasmdem P (2004) Influence of wood extractives on moisture sorption and wettability of red oak (Quercus Rubra), Black Cherry (Prunus serotina), and Red Pine (Pinus Resinosa). Wood Fiber Sci 36(4):483-492

Oberhofnerova E, Panek M (2016) Surface wetting of selected wood species by water during initial stages of weathering. Wood Res 61(4):545-552

Qin Z, Gao Q, Zhang ShF, Li JZ (2014) Surface free energy and dynamic wettability of different machined poplar wood. Wettability Mach 9(2):3088-3103

Scheikl M, Dunky M (1998) Measurement of dynamic and staue contact angles on wood for the determination of its surface tension and the penetration of liquids into the wood surface. Holzforschung 52(1):89-94

Tudor EM, Barbu MC, Petutschnigg A, Réh R, Kristák L (2020) Analysis of larch-bark capacity for formaldehyde removal in wood adhesives. Int J Environ Res Public Health 17(3):764

Wenzel RN (1936) Resistance of solid surfaces to wetting by water. Ind Eng Chem 28:988-994

Young T (1805) An essay on the cohesion of fluids. Philos Trans R Soc Lond 95(1805):65-87

Zenkiewicz M (2007) Methods for the calculation of surface free energy of solids. J Achiev Mater Manuf Eng 24(1):137-145

Publisher's Note Springer Nature remains neutral with regard to jurisdictional claims in published maps and institutional affiliations. 